\title{
Memórias de infância na escola pelo avesso do tracejado das normativas de gênero, sexualidade e desenvolvimento
}

\author{
Memories of childhood in school inside out the \\ dashed of gender, sexuality and development
}

norms

\section{Memorias de la infancia en la escuela al revés de la serie de normas de género, sexualidad y desarrollo}

\author{
Bruno do Prado Alexandre ${ }^{1}$ \\ Raquel Gonçalves Salgado²
}

DOI: http://dx.doi.org/10.20435/serie-estudos.v20i52.1344

\begin{abstract}
Resumo: Este artigo pauta-se em discussões críticas sobre o modelo de desenvolvimento respaldado na cronologia movida pelo progresso e integrante do discurso de desenvolvimento econômico no qual se estruturam os Estados-Nação. Articulada a essas discussões, está a noção de uma infância ideal como um dos pilares de sustentação das políticas curriculares e das práticas educativas voltadas às crianças. Os modelos de desenvolvimento e de infância são postos em discussão pelo viés do gênero e da sexualidade como interrogantes para problematizar estatutos de sujeito, fundamentados em regimes de inteligibilidade de corpos e vidas. Desse modo, analisamos memórias de infância de travestis, marcadas por dissidências em relação às normativas de gênero na escola, vigentes nos currículos, na organização dos espaços, tempos e relações pedagógicas. A infância, nessas memórias, não é tratada como a retrospectiva da vida nem como a prospecção para o futuro, mas como experiência social que é provocada pelas interrogações do presente a lançar críticas que perturbam as programações do tempo cronológico.
\end{abstract}

Palavras-chave: memórias de infância; gênero; escola.

Abstract: This article is based on critical discussions about the development model supported by the chronology moved by progress and part of the discourse of economic development in which Nation-States are structured. Linked to these discussions is the notion of an ideal childhood as one of the pillars of support for curricular policies and educational practices aimed at children. The models of development and childhood are discussed by the bias of gender and sexuality as

\footnotetext{
${ }^{1}$ Universidade Federal da Grande Dourados (UFGD), Dourados, Mato Grosso do Sul, Brasil.

${ }^{2}$ Universidade Federal de Mato Grosso (UFMT).
} 
questions to problematize subject statutes, based on regimes of intelligibility of bodies and lives. Thus, we analyze transvestite childhood memories, marked by dissent regarding gender norms in school, prevailing in curricula, in the organization of spaces, times and pedagogical relations. Childhood, in these memories, is treated neither as a retrospective of life nor as a prospect for the future, but as a social experience that is provoked by the interrogations of the present to cast criticisms that disturb chronological time schedules.

Keywords: childhood memories; gender; school.

Resumen: Este artículo se basa en discusiones críticas sobre el modelo de desarrollo, en base a la cronología impulsada por el progreso y parte del discurso del desarrollo económico en el que se estructuran los Estados-Nación. Vinculada a estas discusiones está la noción de una infancia ideal como uno de los pilares de apoyo a las políticas curriculares y a las prácticas educativas dirigidas a los niños. Los modelos de desarrollo y de infancia se discuten por el rumbo de género y sexualidad como preguntas para problematizar los estatutos de sujetos, basados en regímenes de inteligibilidad de cuerpos y vidas. Por lo tanto, analizamos las memorias de la infancia de travestis, marcadas por la disidencia con respecto a las normas de género en la escuela, prevaleciendo en las políticas curriculares, en la organización de espacios, tiempos y relaciones pedagógicas. La infancia, en estas memorias, no se trata como una retrospectiva de la vida ni como una perspectiva para el futuro, sino como una experiencia social provocada por los interrogatorios del presente para emitir críticas que perturban la programación del tiempo cronológico.

Palabras clave: memorias de la infancia; género; escuela.

\section{INTRODUÇÃO}

O desenvolvimento humano é um dos discursos privilegiados no campo da educação e atravessa as políticas educacionais, os currículos, as propostas e as práticas pedagógicas, sobretudo quando a infância está em foco. Pensar em desenvolvimento humano implica em reportar-se à ideia de um processo que avança para um estado de perfeição, ou seja, uma trajetória cujo telos é o atingimento do estágio mais evoluído do que os anteriores. Portanto o futuro é a promessa da perfeição, o presente, o tempo dos investimentos para a otimização dessa promessa, e o passado, o que deve ser abolido.

Este artigo pauta-se em discussões críticas sobre esse modelo de desenvolvimento, respaldado na cronologia do progresso e integrante do discurso de desenvolvimento econômico no qual se estruturam os Estados-Nação, desde o capitalismo industrial. Articulada a essas discussões, está a noção de uma criança ideal-típica (BURMAN, 2008) como um dos pilares de sustentação dos discursos de educação das crianças, que perpassa as políticas curriculares e as práticas educativas e, por esta razão, apresenta-se como uma das questões centrais para 
o debate aqui ensejado. Os modelos de desenvolvimento e de infância são postos em discussão pelo viés do gênero e da sexualidade como interrogantes para problematizar estatutos de sujeito, fundamentados em regimes de inteligibilidade de corpos e vidas (BUTLER, 2016b). Assim, debruçamo-nos sobre memórias de infância de pessoas que, no presente da vida adulta, vivem as experiências da travestilidade. Memórias estas que são marcadas por dissidências em relação às normativas de gênero e têm a escola como espaço social de relações e pedagogias orientadas à disciplina, ao escrutínio e à educação dos corpos dentro dos regimes de inteligibilidade que sustentam essas normativas. A infância, nessas memórias, não é tratada como a retrospectiva da vida nem como a prospecção para o futuro, mas como experiência social que, em sua condição pretérita, é provocada pelas interrogações do presente a lançar críticas que perturbam as programações do tempo cronológico, tal como uma "reminiscência que relampeja no momento de um perigo" (BENJAMIN, 1985, p. 224).

O foco da discussão está nos dispositivos acionados pela escola, que cerceiam, rechaçam e produzem o desaparecimento social de corpos que escapam das programações de gênero e sexualidade entranhadas nos espaços-tempos, na organização da rotina, nas aulas, nas relações presentes no interior da instituição escolar.

\section{MODELOS DE DESENVOLVIMENTO E INFÂNCIA COMO PILARES DOS CORPOS E DOS GÊNEROS INTELIGÍVEIS NA ESCOLA}

O capitalismo industrial é o berço do discurso do desenvolvimento como validação do crescimento, de processos que avançam e se aperfeiçoam. Na esfera econômica, ressalta Erica Burman (2008), o desenvolvimento está atrelado à maximização e ao acúmulo de lucro. Partícipe do berço do Estado-Nação no capitalismo moderno, o discurso desenvolvimentista escoa para a vida humana e se consagra como um qualificativo importante para a sua compreensão. Sob o selo da ciência psicológica, o desenvolvimento humano recapitula a ideia de otimização e avanço que o desenvolvimento econômico declara. Em torno desse discurso, aglutinam-se teorias psicológicas que inspiram práticas sociais, das quais destacamos as que são vividas nos contextos educativos, em especial, a escola.

No bojo dessa matriz discursiva, está uma noção de infância que desponta como o ideal para que o desenvolvimento regido pelo progresso se efetive, im- 
plantando um sentido único para a vida, em que o passado é o germe do futuro promissor. Trata-se de uma infância simbolizada como modelar, encarnada em uma criança imaginária arrancada da história, das condições e das relações sociais. Essa infância prototípica é investida simbolicamente pelo atributo da inocência, que fundamenta e requer a proteção dos adultos, prática social que se desdobra e perpassa diferentes instituições sociais, como a família, a escola e o Estado. A produção dessa criança ideal-típica mobiliza em torno de si um conjunto de ações e relações afetivas e culturais, das quais são obliteradas as condições das crianças, em seus mundos de vida, nos modos como as suas pertenças raciais, étnicas, de classe social, territoriais e as suas experiências de gênero e sexualidade marcam as suas existências (BURMAN, 2008). Por ser assumida como infância genuína, as crianças que não se alinham a esse ideal são marcadas, desde muito cedo, como aberrações, portadoras de desvios comportamentais que denunciam falhas no desenvolvimento, já que a sua trajetória em direção à perfeição passa a ser interrompida. As diferenças e dissonâncias são, assim, definidas como patologias, em função de suas fugas ao curso regular do desenvolvimento regido pela norma da vida.

Developmental psychology makes specific contributions to this tendency to pathologise differences from supposed norms because of its desire to plot the regular, general course of development. Specific aberrations from that course are then treated, in a circular argument of self-confirmation, as offering useful clues about the general, rather than, say, showing its limits. (BURMAN, 2008, p. 50) ${ }^{3}$.

Na escola, as inscrições dessas aberrações nos corpos das crianças, que não seguem os roteiros previstos do desenvolvimento e da infância ideais e normativos, tornam-se práticas corriqueiras. Michel Foucault (2006), em seus estudos sobre a sexualidade, dedica-se a analisá-la como um discurso que opera como dispositivo de poder a se proliferar, na sociedade moderna ocidental, de modo capilar, por todo o tecido social. Na instituição escolar, a capilaridade discursiva da sexualidade não é diferente e seu alvo privilegiado, de penetração infinita, é a infância. Por todos os

\footnotetext{
${ }^{3}$ A psicologia do desenvolvimento faz contribuições específicas a essa tendência para patologizar as diferenças a partir de normas supostas porque seu desejo é traçar o regular, o curso geral do desenvolvimento. Aberrações específicas desse curso são, então, tratadas, em um argumento circular de autoconfirmação, como forma de oferecer mais pistas úteis sobre o geral do que, digamos, mostrar os seus limites (tradução nossa).
} 
lados e cantos, tempos e rotinas, a vida na escola é atravessada pela sexualidade. A insistência de sua presença está no modo exaustivo como os espaços, o mobiliário, as aulas são organizadas para a disciplina, a vigilância, a fiscalização e a captura dos corpos infantis a serem perscrutados, sobretudo aqueles que fazem acionar os sinais de alerta para o que borra a imagem idealizada da criança-inocente. Nessa rede de poderes, os corpos infantis transformam-se em "artefatos biopolíticos" (PRECIADO, 2013, p. 98). O corpo da criança aliena-se dela própria, torna-se um corpo estranho ao qual ela já não tem mais direito, na medida em que este lhe é confiscado pelo dispositivo da sexualidade acionado pelas mais diversas instituições sociais que ocupam a sua vida, dentre as quais, está a escola.

No âmbito do Estado, esses modelos de desenvolvimento e de infância têm sedimentado políticas de currículo fortemente alinhadas à produção de uma subjetividade empreendedora neoliberal, como se pode notar na mais recente política do Ministério da Educação, conhecida como Base Nacional Curricular Comum (BNCC), cujo objetivo é a implantação dos conteúdos básicos a serem ensinados, da Educação Infantil ao Ensino Médio, em todo o território nacional. Reportando-nos ao seu texto, temos o que segue: "[...] um documento de caráter normativo que define o conjunto orgânico e progressivo de aprendizagens essenciais que todos os alunos devem desenvolver ao longo das etapas e modalidades da Educação Básica" (BRASIL, 2018, p. 7, grifo dos autores). Direitos de desenvolvimento e de aprendizagem de bebês, crianças, adolescentes e jovens são fios condutores dessa política e estão, de forma evidente, pautados na perspectiva do desenvolvimento como maximização da vida e da infância como tempo de instrumentalização e preparação para o futuro. Nesses enquadres, os direitos confundem-se com um modo compulsório de ser e viver, como um dever-ser traduzido em competências individuais a serem aprendidas para a inserção das crianças, dos adolescentes e dos jovens na lógica produtivista do mercado como regra única e absoluta da educação e da vida social. As bases da educação passam a estar atreladas a parâmetros de maximização e eficiência sustentados pela economia de mercado, principalmente quando a utilidade é o critério para a avaliação de necessidades fisiológicas e psicológicas, o que, para Burman (2008), anuncia o triunfo do utilitarismo.

O investimento nas competências individuais põe no centro do processo educativo a produção de uma subjetividade empreendedora que assume hege- 
monia e tem relações estreitas com os modelos mais amplos de desenvolvimento econômico dos Estados-Nação. O apelo aos direitos do desenvolvimento, na BNCC, supõe e declara o que é melhor para a infância, a adolescência e a juventude, entretanto, o ideal reivindicado é um único modo de viver e ser que se consagra como válido e inteligível ao jogar por terra os modos de vida diversos e plurais, marcados por processos de desenvolvimento que estão longe de corresponder à lógica uníssona do mercado global (BURMAN, 2009).

O desenvolvimento impulsionado pela ideia de progresso respalda-se numa ontologia cujo paradigma é a noção de um processo de subjetivação que tem a autossuficiência como o telos da vida. Essa ontologia funda um regime de inteligibilidade que valida corpos, gêneros, sexualidades, culturas, experiências, desenvolvimentos e aprendizagens. Trata-se de um regime de inteligibilidade que, segundo Butler (2016a), abrange um conjunto de normas de vida, sedimentado em um sistema de racionalidade e moralidade liberal, com poder de arbitrar sobre os campos de visibilidade, reconhecimento e aparecimento sociais. Os efeitos desse regime, portanto, voltam-se à demarcação das zonas de normalidade e de abjeção, conforme o que se determina como prerrogativas da vida, que funcionam como dispositivos regulatórios dos espaços de visibilidade e reconhecimento, para as vidas chanceladas pelas normas como válidas e inteligíveis, e dos espaços de opacidade, para as vidas abjetas, que borram as normas.

Esse regime de inteligibilidade apropria-se do gênero ao validá-lo com base nos princípios de coerência e alinhamento com o sexo marcado pelo corpo biológico e o desejo (BUTLER, 2016a). As performances de gênero, que abarcam discursos e linguagens corporais, produzem, pela via da reiteração, os gêneros inteligíveis e normativos, validando corpos masculinos e femininos dentro de uma estrutura binária, heteronormativa e patriarcal do gênero. Cabe lembrar que essas performances compõem os roteiros e os conteúdos de aprendizagem das crianças, os currículos e a organização dos espaços, tempos e relações nas escolas, de modo a pôr em funcionamento programações de gênero que mantêm e perpetuam modelos de desenvolvimento e infância respaldados em corpos inteligíveis. Por outro lado, essas performances também podem produzir fissuras e dobras nessas programações de gênero, que põem a ver o abjeto, o avesso da norma, e, ao mesmo tempo, o rechaço que a sustenta como parte constitutiva do jogo performativo (BUTLER, 2015). 
Ainda que os esforços para a incorporação de ideais normativos de corpos, gêneros e vidas sejam intensos e tenham a escola como um de seus contextos privilegiados de aprendizagem, as possibilidades de desencarrilhar e escapar por trilhas que não estão previstas nos roteiros escritos e prescritos por um dever-ser existem, resistem e têm aparecimento social.

\section{NO EMARANHADO DAS NORMAS E NA TESSITURA DAS MEMÓRIAS DE INFÂNCIA, OS CORPOS DISSIDENTES APARECEM NA ESCOLA}

As memórias de infância na escola, discutidas neste texto, fazem parte de uma pesquisa que se dedica a analisar as narrativas das infâncias de cinco travestis ${ }^{4}$, no sentido de compreender suas trajetórias escolares, marcadas por modificações corporais impulsionadas pelo processo de travestilidade, vivenciado ou não no espaço institucional da escola (ALEXANDRE, 2017). Nessas narrativas, ecoam diversos discursos normativos que atravessam as experiências de cada uma das pessoas envolvidas, que, à sua maneira, vivem claras situações de preconceito, violência e discriminação, amalgamadas a resistências entrelaçadas com relações de poder que perpassam o cotidiano na escola.

Nessas memórias de infância, deparamo-nos com a transmissibilidade do inenarrável nos corpos de crianças, nos modos como esses corpos resistem às molduras do gênero, fazendo destas a rememoração de infâncias que reclama a insurgência do passado contra o presente, o tempo que forja o esquecimento, como possibilidade de transformá-lo e reinventá-lo. Convém destacar que as memórias de infância, neste texto, são entendidas de forma distinta das lembranças de experiências pretéritas. São memórias compreendidas como narrativas do presente, que se curvam para os apelos do passado como forma de libertá-lo do esquecimento, não no sentido de descrevê-lo como de fato aconteceu (BENJAMIN, 1985), mas na forma como ele responde às inquietações do presente.

Tempos e espaços destacam-se nessas narrativas, a exemplo do recreio, das brincadeiras, das aulas de Educação Física, do uso do banheiro, do momento da chamada, dos campeonatos e das composições de grupos para a realização de trabalhos escolares. Esses corpos, que desde a infância destoam dos ideais

\footnotetext{
${ }^{4}$ Em função do escopo deste artigo, analisamos as narrativas de apenas quatro participantes da pesquisa.
} 
normativos de gênero, sexualidade, infância e desenvolvimento, denunciam, no tempo presente, o quanto a escola pode se configurar como um lugar punitivo para aquelas e aqueles que borram as fronteiras rígidas de gênero.

O processo de produção das memórias aqui discutidas aponta para aspectos em comum, vivenciados por diferentes pessoas, em momentos e lugares distintos, e que se assemelham pela hostilidade sentida no espaço escolar. Nesse sentido, Jully Andrews, Suzi Bellison, Adriana Liário e Dê Silva compartilham, no contexto da pesquisa, suas memórias de infância na escola como formas de resistência às violências experimentadas e como denúncias ao que tem sido tão naturalizado no cotidiano escolar.

As memórias de Jully Andrews sobre a infância, a partir do tempo presente, reportam-se a situações vividas aos treze anos de idade na escola. Os sentidos produzidos sobre esse passado voltam-se às violências que evoluíram de ofensivas verbais a agressões físicas, as quais, ao serem denunciadas à coordenação pedagógica da escola, são reiteradas e legitimadas, na medida em que a própria coordenadora chancela essas violências, marcando o corpo dissidente da criança como abjeto ao confirmar a nomeação de viadinho.

Jully Andrews: [...] aconteceu um fato uma vez, eu fui reclamar [...] que o aluno tava me enchendo o saco, chamando de viadinho e me empurrou, e foi brigar comigo nos corredores durante o recreio, eu fui reclamar pra [...] coordenadora que ficava ali de olho em tudo, aí que o aluno tinha me chamado de viadinho, brigado comigo, empurrado, não sei o quê, aí ela olhou na minha cara e falou: "Mas você não é viadinho mesmo?". Assim, eu fui reclamar porque tinha acontecido uma briga comigo, me jogou pelo canto, e me xingou tudo, todo mundo falava as coisas, eu tinha que aceitar sempre, quando eu retruquei, resolvi reclamar a [...] coordenadora falou: "Mas você não é viadinho mesmo?". Não fez nada, não tomou nenhuma atitude em relação ao fulano que tinha me xingado e tudo, daí eu saí da sala da coordenação e fui pra sala de aula, porque ia ficar no pátio, no recreio, apanhando dos outros, o filho de uma égua do guri tava lá enchendo o saco, toda hora e eu fui lá reclamar, ele ia me dar um cacete ainda, saí da coordenação e fui direto pra sala de aula, porque senão de repente ele me dava um pau ainda, no recreio ainda.

O escrutínio do passado acerca daquilo que é vivido na escola traz à tona o corpo de criança de Jully como aquele que apenas pode aparecer sob o signo do grotesco, selado pelo discurso da coordenadora pedagógica como um estigma posto em circulação nesse espaço social. A reiteração do discurso é viado mesmo 
perpetra a declaração de que não se pode ser outra coisa além daquilo que já foi nomeado, como forma de autorizar as violências que se voltam contra a criança, cujas performances de gênero fogem dos roteiros previstos para o desenvolvimento infantil inteligível. Destoar do corpo normal, cuja natureza deve estar alinhada ao gênero e ao desejo, analisa Deborah Britzman (1999), desestabiliza o significado estável que ele assume nos discursos educacionais assentados na ideia de desenvolvimento.

As marcas do estigma serão localizadas no corpo ambíguo e indeterminado - nas entrelinhas desses enunciados esconde-se a ideia de que as travestis apresentam um excesso de gênero; e na prática social que assumirá maior visibilidade na sociedade, ou seja, a prostituição - no não-revelado dessa visibilidade, vê-se a ideia de que os corpos das travestis são lugares de excessos de vícios [...] Estigma e abjeção travesti encarnam-se no corpo, tal como os hormônios e a prótese de silicone. São, portanto, marcas corporais que se mostram e se escondem através da ambiguidade e da indeterminação. Homem? Mulher? Homossexual? Transexual? Travesti? Surgem como ameaça à pretensa coerência do sistema sexo/gênero, à suposta inteligibilidade dos gêneros e à fictícia verdade das categorias homem/mulher. (VERAS; GUASCH, 2015, p. 43).

As memórias de Jully são narrativas dessas marcas corporais que recebem o selo do estigma na escola. Nessa tessitura, ao desfiar as linhas de suas experiências na escola, Jully narra que o processo corporal de construção do feminino travesti acentua vertiginosamente as opressões nesse espaço. O aspecto grotesco e abjeto do corpo que interroga e desestabiliza faz urgir o funcionamento da norma, que aparece sob a forma da legitimação do estigma como resposta aos ecos desordeiros emanados desse corpo ambíguo.

Os sentidos produzidos em torno desse corpo abjeto de criança, marcado pelo estigma, intensificam os desafios das práticas e das relações na escola, que não se restringem aos espaços destinados às aprendizagens dos conteúdos propriamente escolares, uma vez que o uso do banheiro, como se pode notar no excerto abaixo, destaca-se como uma prática pedagógica que aciona, simultaneamente, as aprendizagens das programações de gênero, demarcadoras da inteligibilidade dos corpos que transitam na escola e dos espaços que os comportam. As transformações do corpo marcado pela biologia como masculino em direção ao que se define como feminino evocam ainda mais as situações de segregação e violências. 
Jully Andrews: [...] os colegas que não aceitavam, principalmente depois que afeminei, teve os problemas mais sérios, tive as dificuldades nos banheiros, tinha as dificuldades de fazer um trabalho em grupo, se era as meninas, elas de repente tinha uns bloquinhos, se era pra fazer um trabalho direcionado, tipo, o professor falava, os meninos vai fazer um trabalho referente a um conteúdo e as meninas a tal conteúdo [...] tinha problemas, dificuldade porque eles não me aceitavam no grupo pra fazer o trabalho junto, como não era pra me misturar, então, era difícil, acabava tendo que o professor obrigar, porque era os meninos com os meninos e as meninas com as meninas, então, ele obrigava a aceitar, aí eu ficava no canto.

A escola, nas memórias das travestis, aparece como um espaço, cotidianamente, organizado em torno do ensino das normas regulatórias de gênero e de sexualidade por meio das demarcações e segregações binárias, que podem ser sentidas e vividas tanto no uso do banheiro quanto na realização de trabalhos escolares e nas aulas de Educação Física.

Suzi Bellison: Eu lembro assim vagamente, que teve uma vez, acho que eu tava na quarta série, eu estudava na escola pública, tiveram que chamar minha mãe na escola. Nessa época, não tinha coisa formada na minha cabeça de esporte, eu não tinha escolhido um esporte pra mim seguir, na escola que eu estudava não tinha as disciplinas assim estabelecidas. Cada dia, a gente fazia uma coisa, só que na hora das brincadeiras eu queria brincar só com as meninas, eu queria pular corda, pular elástico, queria brincar de queimada, eu não queria estar lá jogando futebol com os guri, e a coordenação da escola começou a achar estranho aquilo ali, chamaram minha mãe na escola pra conversar. Minha mãe ficou abalada [...] foram jogando tudo em cima dela, e ela ficou abalada, ela nem sabia como me passar isso. Ela ficou, foi agressiva comigo, só que a partir desse momento eu vi que eu tinha que tomar uma atitude, eu com dez anos, tinha que tomar uma atitude, pra mostrar pra ela que eu sendo daquele jeito não ia influenciar em nada na minha vida que eu ia conseguir viver normalmente. Comecei a jogar vôlei e falei pra ela: "Mãe, eu posso ser assim do jeito que eu sou, a senhora tá vendo, eu vou pro campeonato, eu ganho medalha, eu ganho medalha de destaque, a senhora não precisa ficar preocupada!". A minha forma de mostrar pra ela foi essa, através do esporte.

Suzi Bellison: Eu lembro de uma coisa que ficou muito marcado na minha vida, e que me deixou muito magoado mesmo, eu praticamente entrei em depressão, eu jogava vôlei. Meu último ano de juvenil fui fazer uma seletiva em Lucas do Rio Verde, pra ir pra seleção mato-grossense, só que nessa época eu já estava muito afeminada, já pintava a unha, tirava sobrancelha, 
cabelo tava crescendo, já descoloria os pelos da perna, já usava roupa mais apertada, já tava andrógena. Eu me dediquei pra seletiva porque era meu último ano e eu queria muito ir pra essa viagem, e eu fui selecionada entre os nove atletas que iam viajar. Quando meu nome chegou na federação mato-grossense de vôlei em Cuiabá, ele viu meu nome lá, Wagner Moreira Barros, o presidente da federação me vetou. Ele falou que eu não ia, podiam tirar meu nome dali, que eu ia envergonhar o estado de Mato Grosso.

A Educação Física ocupa, entre as outras disciplinas, o espaço-tempo na escola em que os corpos mais aparecem e as performances de gênero e as sexualidades se mostram mais intensas e vivas. Não é à toa que ela se destaca como a disciplina que mais se esforça em normatizar os corpos das crianças e dos jovens, de modo a acionar, prontamente, o sinal de alerta quando a diferença se faz notar, com o propósito de pôr a norma em funcionamento. Assim, a produção de verdades está profundamente implicada nos saberes e nas práticas dessa disciplina, quando, por exemplo, "gostar de futebol é considerado quase uma 'obrigação' para qualquer garoto 'normal' e 'sadio'" (LOURO, 2014, p. 79, grifos da autora). Por certo, ao se deparar com situações que escapam dessa regra, a criança é nomeada como diferente, como portadora de um corpo estranho, e a suspeita sobre a sua suposta normalidade é levantada. Britzman (1999) afirma que modelos normativos de educação, atrelados à noção de desenvolvimento, preocupam-se em escrutinar o que é percebido como problema para privilegiar o normal. Novamente, estamos diante da produção da abjeção para que a norma, dentro da matriz discursiva da heterossexualidade, ganhe foros de verdade e inteligibilidade.

Importa destacar, ainda, que é na mesa de nascimento que o corpo é significado dentro da binaridade, ou seja, por meio das atribuições de masculinidade ou feminilidade, prefigurando-se como "zonas geradoras da totalidade do corpo" (PRECIADO, 2014, p. 130). Por assim dizer, o corpo, ao ser apropriado pela matriz discursiva de inteligibilidade cultural, só tem sentido como sexuado, de modo que a biologia dos órgãos sexuais é o ponto de apoio da coerência com o gênero, que Ihe confere humanidade e reconhecimento.

O corpo, assim como as relações de gênero e sexualidade, assume, portanto, centralidade ao tratarmos da travestilidade, de como é produzida, sentida e experienciada em corpos biologicamente constituídos e culturalmente significados. É no corpo em que os sentidos atribuídos ao masculino e ao feminino são 
culturalmente produzidos; é nele que as dores, alegrias, prazeres e violências são experimentados, silenciados, dominados ou resistidos.

Para Wiliam Siqueira Peres (2015), é de fundamental importância problematizar como os corpos que escapam da heterossexualidade compulsória e extrapolam as regulações socialmente produzidas em torno da vida e do seu eficaz gerenciamento são tratados e percebidos nessas mesmas relações sociais. Ao embaralhar os códigos convencionados socialmente em relação ao masculino e ao feminino e romper com as fronteiras simbolicamente construídas para demarcar esses gêneros, determinados corpos e pessoas produzem uma pane para aqueles e aquelas que não conseguem lidar com a possibilidade da fluidez identitária. Em suas análises acerca dos juízos que se institucionalizam sobre o corpo no Ocidente, Peres (2015) afirma, ainda, que este está atravessado por dimensões institucionais que predeterminam os seus modos de produção, bem como os circunscrevem em pressupostos salutares de funcionamento, de práticas e de estéticas, em consonância com a matriz de inteligibilidade cultural ancorada em arquétipos heteronormativos. Assim, compreender as travestilidades, embebidas por essas análises e a partir de um viés político, implica no desprendimento de um esforço epistemológico, a fim de identificar como as marcas de masculinidades e feminilidades amalgamam-se e entram em disputas, ao mesmo tempo, em um mesmo corpo que se empenha significativamente em torno daquilo que se entende como feminino.

No plano individual e coletivo, muitas travestis orientam-se e afirmam possuir uma suposta naturalidade no que concerne a marcas entendidas como femininas, o que, na perspectiva de Marcos Renato Benedetti (2005), se relaciona muito mais com percepções e sentidos atribuídos a experiências vivenciadas ainda na infância, quer seja pelas preferências por brincadeiras culturalmente significadas como femininas, quer seja pela inaptidão em atividades que demandam agilidade, força ou agressividade, dimensões que culturalmente se distanciam de uma suposta natureza feminina. Estes elementos aparecem nas memórias de infância das travestis e se produzem nas relações de poder que atravessam discursos de gênero e sexualidade, com efeitos de verdade e normatização sobre os corpos e suas práticas.

Peres (2015) sinaliza que as travestis ultrapassam as fronteiras do socialmente inteligível, sobretudo ao romperem com o alinhamento entre corpo, gênero, 
sexualidade, desejo e práticas sexuais, desordenando a rigidez identitária posta como telos do desenvolvimento humano. Destarte, existe em torno da construção dos corpos travestis uma provisoriedade que guia as práticas e as intervenções.

O embaralhamento das normas provocado por esses corpos desalinhados, como já discutimos, faz-se notar nos mais diversos espaços e tempos da escola, e o momento da chamada é um deles, quando o nome social incomoda e o seu rechaço é a prova cabal de que o corpo do nascimento tem a palavra final sobre o gênero da pessoa, sua inteligibilidade e reconhecimento social.

Logo nos primeiros dias de aula, durante a chamada, Adriana Liário narra que foi destratada por solicitar ao professor que a chamasse pelo nome social. Segundo ela, o mesmo episódio ocorreu dias antes com duas amigas travestis que haviam se matriculado com ela, provocando a evasão das duas da escola, o que propriamente se configura como expulsão. Adriana ainda resistiu à situação desrespeitosa e vexatória, entretanto, os deboches e as piadas foram se intensificando no decorrer dos dias. Além disso, o acesso ao banheiro feminino e as roupas também foram obstáculos para o trânsito livre de seu corpo nos espaços da escola, já que a instituição passou a exigir o uso da calça comprida, proibindo o vestido longo, roupa com a qual costumava se apresentar às aulas.

A escola, por meio das suas negações, privações e silenciamentos ante situações de violência e preconceito, em especial, contra as estudantes travestis, analisa Adriana Sales (2012), acaba por legitimar um espaço insólito. Nesse cenário, muitas dessas estudantes não se encontram, na maioria das vezes, preparadas para lidar com essas violências, no sentido de enfrentá-las, principalmente se considerarmos que sua recorrência é cotidiana.

O que foge ao modelo hegemônico estabelecido é submetido à pedagogia da violência e da dor como tentativa de correção e retidão. Na escola, tais pedagogias são praticadas pelos educadores nas "melhores das intenções", pensando na preparação e inserção social dos(as) jovens em uma cultura heteronormativa, sendo esta também uma cobrança da sociedade. (ANDRADE, 2012, p. 248, grifo do autor).

No entendimento de Luma Nogueira de Andrade (2012), os discursos dos docentes, gestores e estudantes relegam a identidade travesti ao campo da anormalidade e, por conseguinte, à marginalidade. O contexto de não adequação e não enquadramento a um hegemônico arquétipo de masculinidade, bem como 
a indocilidade de seus corpos, fomenta, de maneira bastante fértil, toda sorte de violências e discriminações, em especial no espaço escolar. A hostilidade cultivada contra essas pessoas, nesse ambiente, acaba por favorecer um processo de evasão/ exclusão, uma vez que a escola interage com todos esses atravessamentos ao legitimar essas violações e promover o desaparecimento social dos corpos violados.

Ainda a respeito do nome na lista de presença da escola, Dê Silva significa o que viveu como sorte, devido à escola onde estudava adotar uma modalidade diferente de fazer a conferência da presença dos estudantes diariamente, que não era a chamada de cada estudante pelo nome.

Dê Silva: [...] tinha uma lista de chamada que ficava atrás da porta, a gente ia lá e colocava a presença, aí tinha o coordenador da sala que ia e anotava as ausências, quem tava presente ia lá e colocava presente, quem tava ausente depois o coordenador da turma ia e colocava o efezinho.

Cabe ressaltar que tanto o reconhecimento social do nome como o acesso ao banheiro feminino estão entrelaçados com discursos normativos que circulam no espaço escolar e operam no processo de validação dos sujeitos, por meio do qual determinados corpos e vidas passam a ser ou não chancelados como válidos na esfera social.

\section{CONSIDERAÇÕES FINAIS}

As memórias de infância na escola das travestis, participantes da pesquisa em tela, permitem-nos a dialogia entre temporalidades, entre um tempo pretérito, de 20 a 30 anos atrás, e o presente vivido nas escolas, por onde transitam outros corpos de crianças e jovens que, em suas existências dissidentes das normas homogeneizadoras, continuam sendo alvos de violências, preconceitos e negações de direitos. Nesta dialogia, as memórias do passado provocam o assombro do presente, como lembra-nos Butler (2016b), inquietam-no e retiram-no do fluxo contínuo da história para colocá-lo em suspenso diante do desafio de que essa mesma história poderá ser diferente daquela que põe em curso as opressões.

Um dos propósitos da discussão aqui ensejada é tornar problemática a colonização da infância por uma perspectiva de desenvolvimento aliada à ideia de progresso e produtividade como um dos paradigmas no campo da psicologia e da educação, que, prontamente, inspira os currículos e as práticas pedagógicas. Assumimos, portanto, o percurso do estranhamento com o que se valida como 
estatutos da infância e do desenvolvimento por meio do diálogo com memórias situadas no subterrâneo das narrativas que fundam os regimes de inteligibilidade de sujeito e de vida, dadas as dissidências que têm aparecimento social nas corporeidades das crianças e nos modos como jogam com toda uma semiótica das normativas de gênero e da sexopolítica.

Convém ressaltar que nossas indagações não têm a tarefa de proclamar a derrocada do desenvolvimento ou da infância. Ao contrário, elas vão na direção da construção de respostas para problemas que nos movem, comovem e nos implicam diretamente e estão estampados nas desigualdades sociais, nas diversas formas de violência e opressão, na produção de extermínios por regimes totalitários, baseados na declaração de vidas que são ou não válidas, vidas que podem ou não aparecer. Desenvolvimento e infância são termos que se combinam de diferentes maneiras e, na história da infância ocidental, na tradição teórica da ciência psicológica e nos modos como a educação formal se estrutura, formam um par conceitual. A questão, portanto, está nas combinações estabelecidas e naquelas que se consagram como um regime de verdade sobre a vida.

Nas memórias de infância na escola das travestis, os efeitos dessas combinações dos modelos de infância e desenvolvimento em torno da produção de um regime de inteligibilidade multiplicam-se e penetram nos tempos e espaços da escola - no banheiro, nas aulas de Educação Física, na hora da chamada -, fazendo lembrar, cotidianamente, quais são os corpos que importam e cabem na instituição, a que infâncias a escola se destina. Convém destacar as relações existentes entre esse cenário e o texto político da BNCC, base curricular nacional, que se estende para todo o território brasileiro e tem como um de seus fundamentos os direitos de aprendizagem e desenvolvimento. Sob a roupagem dos direitos, percebe-se claramente que o desenvolvimento das crianças e dos jovens se configura muito mais como competências a serem aprendidas para o cumprimento de um dever-ser, estabelecido como a identidade almejada no processo de escolarização e pautada em um conjunto de competências definidas por demandas neoliberais.

Terminamos o texto com o desafio de reativar as combinações da infância com o desenvolvimento, na acepção de Isabelle Stengers (2017), que implica em reaver o que elas confiscaram das existências que não cabem dentro dos estatutos estabelecidos, de dar aparecimento social ao que é sufocado porque 
não tem validade para existir. Por estas razões, importa-nos reativar, também, a escola no movimento do fluxo da contramão, da contracorrente, dos espaços de contestação de sistemas de pensamento que ensinam a abominar as diferenças.

\section{REFERÊNCIAS}

ALEXANDRE, Bruno do Prado. Sobre corpos que "não podem" aparecer: memórias de escola nas narrativas de pessoas travestis. Orientadora: Raquel Gonçalves Salgado. 2017. 146f. Dissertação (Mestrado em Educação) - Universidade Federal de Mato Grosso, Rondonópolis, MT, 2017.

ANDRADE, Luma Nogueira de. Travestis na escola: assujeitamento e resistência à ordem normativa. Fortaleza: Editora da UFC, 2012.

BENEDETTI, Marcos Renato. Toda feita: o corpo e o gênero das travestis. Rio de Janeiro: Garamond, 2005.

BENJAMIN, Walter. Obras Escolhidas: magia e técnica, arte e política. 2. ed. São Paulo: Brasiliense, 1985. V. 1.

BRASIL. Ministério da Educação. Base Nacional Comum Curricular: versão final revista. Brasília-DF: MEC, 2018.

BRITZMAN, Deborah. Curiosidade, sexualidade e currículo. In: LOURO, Guacira Lopes (Org.). O corpo educado: pedagogias da sexualidade. Belo Horizonte: Autêntica, 1999. p. 83-111.

BURMAN, Erica. Desenvolvimento desejado? Contribuições psicanalíticas para o antidesenvolvimento psicológico. A peste, São Paulo, v. 1, n. 2, p. 269-94, jul./dez., 2009.

BURMAN, Erica. Developments. Child, image and nation. London; New York: Routledge, 2008.

BUTLER, Judith. Problemas de gênero: feminismo e subversão da identidade. 10. ed. Rio de Janeiro: Civilização Brasileira, 2016 a.

BUTLER, Judith. Quadros de guerra: quando a vida é passível de luto?. 2. ed. Rio de Janeiro: Civilização Brasileira, 2016b.

BUTLER, Judith. Cuerpos que importan: sobre los límites materiales y discursivos del "sexo". 2. ed. Buenos Aires: Paidós, 2015. 
FOUCAULT, Michel. História da sexualidade l: a vontade de saber. 17. ed. Rio de Janeiro: Edições Graal, 2006.

LOURO, Guacira Lopes. Gênero, sexualidade e educação: uma perspectiva pósestruturalista. 16. ed. Petrópolis, RJ: Vozes, 2014.

PERES, Wiliam Siqueira. Travestis brasileiras: dos estigmas à cidadania. Curitiba: Juruá, 2015.

PRECIADO, Beatriz. Manifesto contrassexual. São Paulo: n-1 edições, 2014.

PRECIADO, Beatriz. Quem defende a criança queer? Jangada-crítica, literatura, artes, Viçosa, n. 1, p. 96-99, jan./jun. 2013.

SALES, Adriana. Travestilidades e escola nas narrativas de alunas travestis. Orientador: Leonardo Lemos de Souza. 2012. 114f. Dissertação (Mestrado em Educação) Universidade Federal de Mato Grosso, Rondonópolis, MT, 2012.

STENGERS, Isabelle. Reativar o animismo. Caderno de Leituras, n. 62, p. 1-15, maio 2017.

VERAS, Elias Ferreira; GUASCH, Oscar. A invenção do estigma travesti no Brasil (19701980). História, histórias, Brasília, v. 1, n. 5, p. 39-51, 2015.

\section{Sobre os autores:}

Bruno do Prado Alexandre: Doutorando em História pela Universidade Federal da Grande Dourados (UFGD). Mestre em Educação pela Universidade Federal de Mato Grosso, Campus de Rondonópolis. Docente da Faculdade de Ciências Sociais Aplicadas do Vale do São Lourenço (EDUVALE).E-mail: brunoroo125@hotmail.com, Orcid: http://orcid.org/0000-0003-2465-1628

Raquel Gonçalves Salgado: Doutora em Psicologia pela Pontifícia Universidade Católica do Rio de Janeiro (PUC-Rio). Professora Associada da Universidade Federal de Mato Grosso (UFMT), Campus de Rondonópolis. E-mail: ramidan@terra.com.br, Orcid : https://orcid.org/0000-0002-8730-3025

\section{Recebido em 12 de setembro de 2019. Aprovado em 18 de setembro 2019.}


